\title{
Design and User Acceptance Evaluation of An Intelligent Electronic Navigation Crutches System for Elderly Mobile Healthcare
}

\author{
Chiung-Wei Huang a,b ${ }^{\mathrm{a},}$ Yen-I Chiang ${ }^{\mathrm{c}, *}$, Chien-Lung Hsu ${ }^{\mathrm{c}}$, Yu-Hao Chuang ${ }^{\mathrm{c}}$, Cheng-Yuan Chang ${ }^{\mathrm{a}}$ \\ ${ }^{a}$ Department of Electrical Engineering, \\ Chung Yuan Christian University, Jhongli 320, Taiwan, R. O. C. \\ ${ }^{\mathrm{b}}$ Department of Digital Multimedia Design, \\ Chien Hsin University of Science and Technology, Jhongli 320, Taiwan, R. O. C. \\ ${ }^{\mathrm{c}}$ Department of Information Management, \\ Chang Gung University, Taoyuan 333, Taiwan, R. O. C. \\ *Corresponding Author: yenichn@mail.cgu.edu.tw
}

\begin{abstract}
Many countries are facing with the problem of rapid aging societies, thus it is essential to find ways to alleviate this challenge. This paper introduces a user friendly, inexpensive, and nonintrusive Electronic Navigation Crutches (ENC) system that integrates the latest technologies such as Text-to-Speech, global positioning system, mobile communications and wireless technologies. The ENC system actively gives personalized navigational instruction (verbally and visually), allowing the elderly to participate in outdoor excursions independently. The ENC system also incorporates the wireless technology, allowing the caregivers to monitor and locate the respective elderly user, and to provide instant reminding massage services through the guidance mobile phones. A technology acceptance model to evaluate and investigate whether the ENC system can be accepted and used by the elderly persons is proposed. Based on the data collected by the questionnaire, the ENC system is perceived to be relatively effortless and practical, and the results have been supported by and in-line with the proposed technology acceptance model.
\end{abstract}

Keywords: Technology Acceptance Model, Navigation System, Crutches, Mobile Healthcare, Sensor.

\section{Introduction}

In recent years, the proportion of the elderly population within various countries has gradually increased, which in terms leads to those countries to transit into aging societies.
The degree of how a society is aging can be classified into three different categories, namely aging society, aged society, and super aged society, based on the proportion of its elderly population. The proportion of elderly population is over $7 \%$ and less than $14 \%$, over $14 \%$ and less than $20 \%$, and over $20 \%$ of its total population, respectively, for aging society, aged society, and super aged society. For instances, Taiwan is already an aging society by September 1993, when the proportion of elderly population is estimated to be over $7 \%$ and the ratio is steadily increasing up to this date. Taiwan is expected to transit into the aged society in 2018 and transit into the super aged society in 2025 [1].

Many successful health care applications have been presented in the literature with the aim to assist caregivers to locate or monitor patients' whereabouts. Healthcare applications based on ubiquitous computing and communication technologies [2-5] can help to get the positions of patients in the hospitals. However, locating the whereabouts of patients outside the hospitals is an important requirement in the health care system design. Thus, some health care applications proposed to track the activities of patients by using RFID (Radio Frequency Identification) technology [6-9]. Nevertheless, most of these health care applications were designed for general patients, and were not design specifically for the elderly persons. The requirements for the elderly are very particular, especially when one also needs to take into account that the equipment might need to be incorporated into the users' daily life. To empower the elderly to actively and independently participate in outdoor and normal daily activities, it is vital for the elderly to be able to find 
assistance in cases of need, find direction of the destination, and find the way home. Common electronic navigation map may be too complicate for the elderly to use and require the user to input correct instructions for them to operate properly. We foresee that elderly persons might be more suited to use a more active device that can preemptively give instructions and monitor for signs for interventions or assistances. Hence we believe that a convenient care monitoring and active navigation system maybe essential for the elderly when they are doing outdoor activities alone.

Consequently, a mobilized care and navigation system, namely Electronic Navigation Crutches (ENC) system was developed for the elderly persons when they are engaging outdoor activities independently. The ENC system is a user friendly and nonintrusive device that can actively give personalized navigational instruction (verbally and visually). The ENC system also incorporates the wireless technology to enable the caregivers to monitor and locate the respective elderly user, and to provide instant reminding massage services through the guidance mobile phones. We envisage that such a system can be accepted and used by the elderly persons who wish to participate in outdoor excursions independently. In this work, we adopted the most widely accepted model, the technology acceptance model (TAM), to test and verify that our system is sufficiently effortless and practical to the elderly users.

\section{System Architecture of the Intelligent Electronic Navigation Crutches System}

A convenient single-chip embedded platform was developed and integrated onto a crutch structure for the elderly user with an external guidance mobile phone for the caregivers of the elderly user included. The system incorporated the Text-to-Speech (TTS) technology, a Liquid Crystal graphical display, a global positioning system (GPS), a Global System for Mobile Communications (GSM), wireless physiological sensing module, and a visual compass icon with voice prompt navigation to enable the elderly persons to return home unaccompanied. Using the GPS, GSM, and wireless physiological sensing modules proposed in our work, the caregivers can successfully identify the location of missing elderly persons and provide assistances to them in due time. The system consists of two subsystems that devised for the two different role players of end-users: the elderly user and the caregivers. The respective hardware is the electronic crutch with the embedded subsystem for the elderly user (see Figure 1 for the prototype of the electronic crutch and see Figure 2 for a detailed illustration of all hardware of the corresponding embedded system) and the guidance mobile phones for the corresponding caregivers respectively.

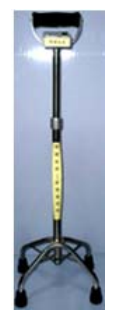

Fig. 1. The Electronic Navigation Crutch.

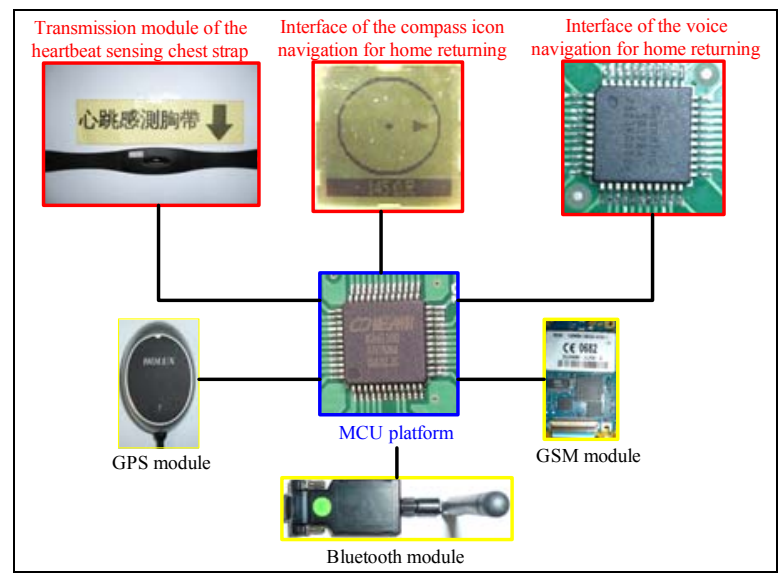

Fig. 2. The diagram of the integrated hardware system.

The subsystem for the elderly user is the electronic navigation crutch with the embedded system, which comprises of five modules: a user interface module, a communication module, a satellite positioning module, a physiological monitoring module, and a single chip extended module. Below are detailed descriptions of each module:

The subsystem for the elderly user is the electronic navigation crutch with the embedded system, which comprises of five modules: a user interface module, a communication module, a satellite positioning module, a physiological monitoring module, and a single chip extended module. Below are detailed descriptions of each module:

1. The user interface module contains an audio component based on the Text-to-Speech technology and a visual component based on a graphical Liquid Crystal Module (LCM). The audio component of this module can generate good voice quality with adjustable pronunciation speed and voice volume. The graphical component can provide clear and distinguishable visual 
instructions for navigation purpose. Furthermore, the module is light in weight and small in size to be embedded onto a crutch.

2. The communication module includes a Bluetooth component and a Global System for Mobile Communications component that allows the system to send and receive Short Message Service (SMS), transmit emergency communication, send out requests for medical assistances when abnormal physiological signals are detected, and can also act as a reminder (convey important short messages to the elderly user).

3. The satellite positioning module consists of an integrated global positioning system that can provide voice navigational instructions, and has the ability to acquire and send the coordinates of current location of the user through the communication module to the caregivers. Some extra useful features of this module are that this module is water resistance and is able to store and integrate information of previously visited locations.

4. The physiological monitoring module consists of a heartbeat sensing chest strap for monitoring the physiological condition of elderly person. This chest strap device is capable of transmitting stress signals though the communication module to the nearest medical facility and the caregivers when any abnormal physiological condition of the wearer is detected. The advantage of using the heartbeat sensing chest strap is that it is easy and comfortable to wear, and well suited for the usages of elderly persons. Furthermore, the chest strap can generate high quality signals that are almost free of noise signals; hence it can monitor the heartbeats of the wearer with high precision and is able to detect occurrences of abnormality quickly.

5. The single chip extended module comprises the Megawin X51 single chip with extra extended interfaces, which enable this chip to coordinate and integrate the above four modules into the subsystem. All calculations, programs' execution and data storages are executed in this module; basically it is the core of this subsystem.

The other subsystem of the electronic navigation crutches is the guidance mobile phone for the caregivers. Basically it utilizes three main modules of a standard smartphone device, which comprises of a user interface module, a communication module, and a satellite positioning module. The device allows the caregiver to send messages to and receive information from the electronic crutch. Furthermore, the device allows the caregiver to track the whereabouts of the elderly user and is able to coordinate immediate responds to the elderly user when detecting of any abnormal physiological signals. Figure 3 is the diagrammatic illustration of this system.

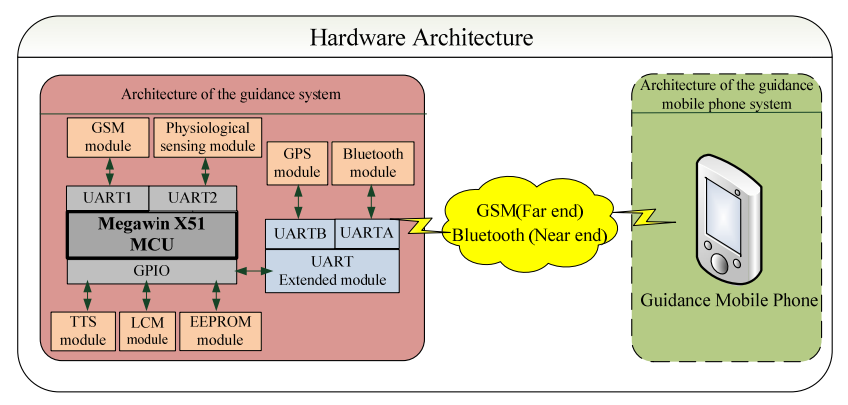

Fig. 3. The structure of the Electronic Navigation Crutches system.

\section{Mobile Healthcare Services for the Elderly}

In terms of the elderly users, the system aims to provide a user friendly and effective application, with simple and intuitive in terms of usages, and non-intrusive in its physical form, and also actively provides navigation instructions and physiological condition monitoring. The elderly might be more prone to have difficulty in finding their way home or might even forget their home address due to possible decline of memory. Hence this system provides a navigational guiding function embedded in a crutch with a simple navigation interface using a compass-like display to indicate direction and distance of each subsequent move. Furthermore, the navigational guiding function also provides verbal instructions synchronously with the compass-like display. An augmented function of this system is the "home path learning" component, this component allows the navigational verbal instructions to be further reinforced through preloaded sites of interest along the way of elderly's usual routes, where places that can visually assist the elderly to identify the correct direction are included into the voice instructions. For example, instead of just saying "turn to the 12 o'clock direction and walk straight for about 30 meters", the system will incorporate the available information and give further instruction by affixing more visible information such as "after passing a convenience store!" or "to reach a park!". The device is light in weight and can be implemented on a relatively low-cost microcontroller, since no built-in electronic map is needed on the electronic crutches subsystem.

An emergency button is installed onto the grip of the 
crutch; the elderly can press this SOS button when in need of assistances. The system will send a SOS short message with the coordinates of the elder's current location to the nearest point-of-care and the caregivers. The system also envisages that an elderly might have chronic diseases or experience physical discomfort (such as heart attack, abnormal blood pressure, or stress) when participates in any outdoor excursion alone. Thus, this system is integrated with a high performance heart rate sensing module for the monitoring of physiological conditions and the detection of physiological abnormality in case of medical emergency. In case of detecting any physiological abnormality, the equipment will automatically sent a SOS short message with current coordinates of the elderly to the nearest point-of-care and the caregivers. The device is comfortable and simple to wear and is not easily dislodged from the wearer.

The system is non-intrusive and not much interplay is required from the prospective of elderly users. The most of the burden of interaction is placed on caregiver. Following is the description of various services provided by the system from the perspective of the caregiver. Caregivers require uploading most of the data such as the coordinates of each location of interest via the GPS of the guidance mobile smartphone, and the phone numbers of the nearby medical stations and corresponding caregivers into the system in advance.

In order to make this system more personalized and more efficient in the ability of guiding the elderly user to home, the system augments the path learning function, enabling the caregivers to store relevant information of distinguishable locational markers along routes that the elderly might travel. Those locational markers will be recorded by the guidance mobile phone when a caregiver accompanies the user to walk a selected route, and the recorded data can be transferred onto the electronic navigation crutches via Bluetooth. After the relevant information has been uploaded, the compass icon navigation function can incorporate the up loaded information into the voice prompt directional instruction, when a user is getting close to the proximity of a preset landmark or intersection.

This system also includes a message reminding service allowing the caregiver to send short message to remind the elderly. Furthermore, to compensate for failing sight of the elderly and possible unfamiliar with the usage of mobile phones, the system will automatically convert the text message into audio speech (with adjustable volume control) via the TTS module.

Through this system, the caregivers can allow the elderly to have the flexibility of participating outdoor excursions independently (which might leads to elderly persons more likely to take parts in outdoor excursions). However, in case of detecting physical discomfort of the elderly (such as heart attack, abnormal blood pressure, or stress) or emergency, the system can inform the caregivers through the services of physiological condition monitoring or emergency assistance function to provide suitable assistances in time. In summary, the advantages of this system are:

1. The compass icon voice prompt function is specifically designed and suitable for the seniors to guide them returning home. The voice prompt makes our system more flexible than general electronic navigation system.

2. A professional heartbeat sensing chest strap is used for monitoring the real time physiological conditions and detecting the abnormal conditions.

3. An emergency SOS button is set on the grip of a crutch. Elderly can press this SOS button for assistance when in need. A SOS short message with seniors coordinates will be sent to the nearest point-of-care nursing station.

4. By setting relevant information in a guidance mobile phone, the path learning function can efficiently assist elderly to find the way home when they got lost.

5. The important message reminding function accompanying with voice prompt makes our system practical useful for the elderly person.

6. Portable in size and low cost make this system attractive and easy to popularize.

\section{Exploring the Elderly Acceptance of the Intelligent ENC System}

In this section, we aim to verify that the Electronic Navigation Crutches is an effective technology that can be accepted and used by the elderly users. We used the most common accepted information technology model, the Technology Acceptance Model (TAM) introduced by Davis et al. [10], to substantiate our claim that our system is acceptable to the elderly users. Although there exist various versions of TAM model in the literature, but primarily it is used to examine or predict users' acceptance of information technologies [11-14]. In our model, we have augmented one extra construct, "perceived value", to our proposed TAM, where we foresee that the cost of the electronic navigation 
crutches might influence the decision whether or not an elderly will use the electronic navigation crutches. The reason behind this is due to the fact that crutches are not an essential device for most of the elderly persons; however, crutches can play supportive and preventive roles when the elderly engaged in daily activities. Hence affordability of the electronic navigation crutches might become an issue when dealing with the acceptance of such a technology.

The proposed conceptual model (as shown in Figure 4) is described in terms of the Technology Acceptance Model (TAM) to reveal the primary motivations for the elderly to use the ENC system. The TAM is a user behavior analysis model proposed by Davis et al. [10] and is based on the Theory of Reasoned Action (TRA) [15]. In the past decades, the TAM has been empirically proven to be a primary model for exploring personal acceptance or usage of a new information technology. Basically our proposed model involves the following four factors that can influence the user's behavioral intention: perceived usefulness, perceived ease of use, perceived value, and attitude. Hereafter we give a briefly introduction for each factor.

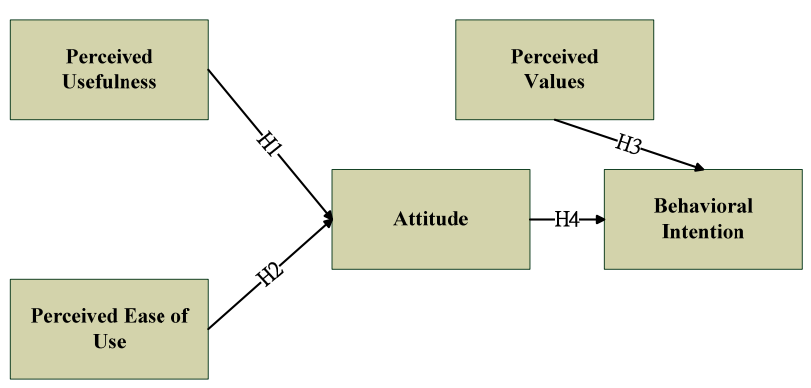

Fig. 4. The proposed conceptual model.

\section{(a) Perceived Usefulness}

The traditional TAM postulates that two cognitive beliefs, namely perceived usefulness and perceived ease of use, will impact individual behavior intention for adopting technology through attitude. According to the definition proposed by Davis et al. [10], perceived usefulness is the degree to which a prospective user subjectively believes that by using a specific system would enhance his (or her) job performance. Perceived usefulness can also be regarded as the relative benefit perceived by the user. For this reason, Rogers [16] considered perceived usefulness as the degree to which an innovation is cognitive to be better than its predecessor. As a consequence, perceived usefulness would impact the user's intention to use the technology through user's attitude.

(b) Perceived Ease of Use
Perceived ease of use is the other potential cognitive belief in the TAM that impacts user's behavior intention for personal acceptance or usage of a new information technology [17]. This factor conveys the extent in which a user's belief in how much effort is expected from the user to invest or the steepness of the learning curve for the new system (or device) to be operable [17, 18]. The earliest interpretation for "perceived ease of use" was by Rogers [16], where it is stated as a term that indicates the extent to which an innovation is deem not to be difficult to learn, understand or perform. Rogers [16] considered the innovation can be seen as a new product or service which would be adopted. Similarly, Zeithaml et al. [19] defined the term perceived ease of use as the extent to which an innovation is considered as not difficult to use or understand. The interpretation of Zeithaml et al. is more appropriate for our proposed model.

\section{(c) Perceived Value}

The role of perceived value has become an increasing concern to the consumer and the seller in today's marketplace [20]. A consumer's decision of whether to use or not to use an item may be influenced by one's perceptions of what is expected in return (i.e., benefits or advantages) and what is expected to give up (i.e., sacrifices). Parasuraman [21] acknowledges "perceived values" as one of the principal measures for gaining competitive benefits. In general, the concept of "perceived values" can be interpreted as the consumer's evaluation of perceived sacrifices and expected benefits when one is to utilize the item or service in question. Zeithaml [22] defined perceived values as a consumer's overall assessment of the utilization of a product or service based on one's perceptions of what is given and what is gained. Numerous researches have indicated that "perceived values" plays a more influential role than either quality or satisfaction [23, 24].

\section{(d) Attitude}

Among various theories proposed in social psychology, TAM was adopted from the (TRA) initially proposed by Fishbein and Ajzen $[15,25]$. In the TRA, "attitude" is used as an individual's favorable or unfavorable feeling towards the object or person of concern. Later, Davis et al. [10] applied the TRA to construct the TAM to measure individual acceptance of technology usage, where "attitude" was defined as an individual's overall belief that the consequences of implementing the behavior and multiplied by the evaluation of those consequences. As shown by previous studies, attitude can be considered to be a critical determinant of human behavior intention [26, 27]. 


\section{Validation of the Intelligent ENC System}

The design and phrasing of questions of our questionnaire survey is adapted from the questionnaires designed in various related studies $[15,17,18,23,24$, 26-29]. The main source of our sample is from Can-Full elder care and rehabilitation center which is a reputable institution with over 15 years of experience in the services of caring for the elderly, and has being accredited by the Taiwan government to be a top rated caring facility, consecutively for the past 11 years. One vital aspect is this facility provides home caring services for the elderly in the greater Tao-Yuan region. Reasons for selecting the caregivers as target of our survey is partly due to elderly users' rational process and expressiveness might have declined and make them unsuitable to give precise answers for our survey. On the other hand, candidates for our questionnaire survey are those active, qualified, professional caregivers for the elderly, who have firsthand, in-depth understandings of the elderlies' behaviors and habits. Furthermore, from their daily involvements and close observations with the elderlies, they can provide opinions that are very close to realistic requirements of the elderlies.

The questionnaire contains two major sections: Part I of the questionnaire has 14 questions that deal mainly with demographic data of the surveyed sample, such as age, sex, education, monthly income, and etc. Part II is the main section of the survey with questions dealing with perceived usefulness, perceived ease of use, perceived value, attitude, and behavioral intention. Every question in Part II asked the sampled individual to assess the extent to which each of the following questions best descriptive of the subject's true feeling. Each question is rated using the five-point Likert-scale, where a response value that ranged from 1 ("extremely disagree") to 5 ("extremely agree"). The IBM SPSS statistics version 22.0 and LISREL version 8.80 software were used for the statistical analysis of the data.

Part II of the questionnaire contains a total of 25 questions that indexed from 1 to 25 and the questions are clustered into 5 segments based on the nature of questions addressing. Each segment comprises of 5 questions that indexed consecutively. The respective topics that this five segments were assessing are (in the order prescribed): perceived usefulness (i.e., The Electronic Navigation Crutches can help me to find the way home accurately), perceived ease of use (i.e., I consider the Electronic Navigation Crutches is easy to use), perceived value (i.e., I think it is worth for me to buy the Electronic Navigation Crutches), attitude (i.e., I think using the Electronic Navigation Crutches to navigate the way home is a good idea) and behavioral intention (i.e., I would like to use the Electronic Navigation Crutches to navigate the way home in the future).

As we have mentioned in the beginning of this section, our questionnaire was designed based on various studies found in the literature, hence a group of carefully chosen experts and scholars were invited to conduct a pre-test for our questionnaire to assure the reliability of questionnaire. The goal is to eliminate any ambiguity and impreciseness from each question. The group consists of eight scholars with domain knowledge in internet technology and extensive experience of healthcare (including four professors, two doctors, and two $\mathrm{PhD}$ candidates). After a revision, all eight participants were then asked to reevaluate the questionnaire again, and they concurred that the final version of the questionnaire could properly measure the intend dimensions that are essential for the evaluation of Electronic Navigation Crutches usage for the elderly. Thus, both content and face validity were deemed adequate.

Subsequently, we apply the Cronbach's alpha statistic to measure the reliability of the proposed questionnaire. In general, a Cronbach's alpha value higher than 0.7 implies high reliability, a value less than 0.35 implies unacceptable reliability and a value between 0.35 and 0.7 implies acceptable reliability. As shown in Table 1, after the deletion of unsuitable items, the Cronbach's alpha values of all constructs in our questionnaire were between 0.505 and 0.663 , which means the reliability of our questionnaire was acceptable.

Table 1. Reliability Comparison of the Scales

\begin{tabular}{||l|c|c|c|c||}
\hline Dimension & $\begin{array}{c}\text { Number of } \\
\text { Questions }\end{array}$ & $\begin{array}{l}\text { Question } \\
\text { Deleted }\end{array}$ & $\begin{array}{l}\text { Cronbach's } \\
\alpha \text { before } \\
\text { deletion }\end{array}$ & $\begin{array}{l}\text { Cronbach's } \\
\alpha \text { after } \\
\text { deletion }\end{array}$ \\
\hline $\begin{array}{l}\text { Perceived } \\
\text { Usefulness }\end{array}$ & 5 & N/A & 0.663 & 0.663 \\
\hline $\begin{array}{l}\text { Perceived } \\
\text { Ease of Use }\end{array}$ & 5 & N/A & 0.645 & 0.645 \\
\hline $\begin{array}{l}\text { Perceived } \\
\text { Value }\end{array}$ & 5 & N/A & 0.553 & 0.553 \\
\hline Attitude & 5 & {$[5]$} & 0.110 & 0.557 \\
\hline $\begin{array}{l}\text { Behavioral } \\
\text { Intention }\end{array}$ & 5 & {$[4][5]$} & 0.328 & 0.505 \\
\hline \hline
\end{tabular}

After the unsuitable questions from the questionnaire to confirm validity and reliability of the content in the pre-test, we then conduct the survey on simple randomly selected sample of elderly caregivers who are working in the 
Can-Full elder care and rehabilitation center. We administered a face-to-face interview to assist the respondents filling out the questionnaire. A total of 63 samples were collected in a period of about two weeks.

Below are the summary of the descriptive statistic of the basic demographic information of respondents, which consisted of gender, age, career, level of education, monthly income, and etc. Among the sample of respondents, approximately $8.1 \%$ were male and $91.9 \%$ were female. Most respondents' ages ranged between 41 and 55; the monthly income of most respondents ranged between 20001 and 30000 (53.2\%); highest level of education attained of most respondents was senior high school (64.5\%). All demographic information of respondents is summarized in Table 2.

Table 2. Demographic Values

\begin{tabular}{|c|c|c|c|}
\hline \multicolumn{2}{|c|}{ Description } & \# of Valid & Percentage \\
\hline \multirow{2}{*}{ Gender } & Male & 5 & $8.1 \%$ \\
\hline & Female & 57 & $91.9 \%$ \\
\hline \multirow{7}{*}{ Age } & $<30$ & 1 & $1.6 \%$ \\
\hline & $31-35$ & 3 & $4.8 \%$ \\
\hline & $36-40$ & 4 & $6.5 \%$ \\
\hline & $41-45$ & 13 & $21.0 \%$ \\
\hline & $46-50$ & 9 & $14.5 \%$ \\
\hline & $51-55$ & 18 & $29.0 \%$ \\
\hline & $>56$ & 14 & $22.6 \%$ \\
\hline \multirow{5}{*}{$\begin{array}{l}\text { Income per } \\
\text { month (Unit: } \\
\text { NT\$) }\end{array}$} & $<10000$ & 1 & $1.6 \%$ \\
\hline & $10001-20000$ & 18 & $29.0 \%$ \\
\hline & $20001-30000$ & 33 & $53.2 \%$ \\
\hline & $30001-40000$ & 9 & $14.5 \%$ \\
\hline & $>40001$ & 1 & $1.6 \%$ \\
\hline \multirow{5}{*}{$\begin{array}{l}\text { Level of } \\
\text { education }\end{array}$} & Elementary school & 4 & $6.5 \%$ \\
\hline & Junior high school & 8 & $12.9 \%$ \\
\hline & Senior high school & 40 & $64.5 \%$ \\
\hline & $\begin{array}{c}\text { Undergraduate } \\
\text { degree }\end{array}$ & 10 & $16.1 \%$ \\
\hline & Master's degree & 0 & $0 \%$ \\
\hline \multirow{2}{*}{$\begin{array}{l}\text { Experience of } \\
\text { taking care the } \\
\text { elderly }\end{array}$} & Yes & 60 & $96.8 \%$ \\
\hline & No & 2 & $3.2 \%$ \\
\hline \multirow{2}{*}{$\begin{array}{l}\text { Crutches } \\
\text { usage for the } \\
\text { caring elderly }\end{array}$} & Yes & 59 & $95.2 \%$ \\
\hline & No & 3 & $4.8 \%$ \\
\hline
\end{tabular}

We then conduct the analysis of variance to determine whether there is significant difference in the responses, due to different class levels of each demographic variable. As the results have indicated, vary large p-values were found across all test results of each demographic variable (such as gender, age groups, income levels, and education levels), which implies that the average responds of different classes of any demographic variable are not different significantly, hence unlikely to influence the outcomes.

\section{Conclusions}

In this research, a mobilized elderly care and navigation system providing functions of compass icon navigation with voice prompt, emergency help communication, abnormal physiological condition detection, home path learning, and important message reminding was developed. As a prototype, this platform has been imbedded to a crutch structure accompanying with a guidance mobile phone for practical use of elderly person. We have tested the system performance and reliability. This system is shown to be a practical and convenient system that is able to provide navigation, monitoring, and assistances for the elderly persons.

This paper has successful demonstrated that a user friendly and nonintrusive Electronic Navigation Crutches system that can actively give personalized navigational instruction (verbally and visually), incorporated with the assistances of caregivers through the wireless technology of guidance mobile phones that allows the caregivers in care of the elderly to be able to monitor, locate, and provide instant massage reminding services to them, can be accepted and used by the elderly persons whom wish to participate in outdoor excursions independently, because the system is perceived to be relatively effortless, practical, and inexpensive, which is verified and supported by the analysis of the data collected by the questionnaire, and the result is demonstrated to be in-line with the proposed technology acceptance model.

\section{References}

(1) Population Policy White Paper, D.o.H. Registration, Editor 2013, Ministry of the Interior: Taiwan, ROC.

(2) Fischer, S., et al., Handheld computing in medicine. Journal of the American Medical Informatics Association, 2003. 10(2): p. 139-149.

(3) Rodriguez, M.D., et al., Location-aware access to 
hospital information and services. Information Technology in Biomedicine, IEEE Transactions on, 2004. 8(4): p. 448-455.

(4) Favela, J., et al., Integrating context-aware public displays into a mobile hospital information system. Information Technology in Biomedicine, IEEE Transactions on, 2004. 8(3): p. 279-286.

(5) Lin, Y.-H., et al., A wireless PDA-based physiological monitoring system for patient transport. Information Technology in Biomedicine, IEEE Transactions on, 2004. 8(4): p. 439-447.

(6) Min, M.C., T.R. Lon, and F.K. Chen, An abnormal situations settlement system for institutional elderly care. 2009.

(7) Lin, C.-C., et al., Wireless health care service system for elderly with dementia. Information Technology in Biomedicine, IEEE Transactions on, 2006. 10(4): p. 696-704.

(8) Lin, C.-C., et al., A healthcare integration system for disease assessment and safety monitoring of dementia patients. Information Technology in Biomedicine, IEEE Transactions on, 2008. 12(5): p. 579-586.

(9) Nath, B., F. Reynolds, and R. Want, RFID technology and applications. IEEE Pervasive Computing, 2006(1): p. 22-24.

(10) Davis, F.D., R.P. Bagozzi, and P.R. Warshaw, User acceptance of computer technology: a comparison of two theoretical models. Management science, 1989. 35(8): p. 982-1003.

(11) Venkatesh, V. and M.G. Morris, Why don't men ever stop to ask for directions? Gender, social influence, and their role in technology acceptance and usage behavior. MIS quarterly, 2000: p. 115-139.

(12) Legris, P., J. Ingham, and P. Collerette, Why do people use information technology? A critical review of the technology acceptance model. Information \& management, 2003. 40(3): p. 191-204.

(13) Venkatesh, V., et al., User acceptance of information technology: Toward a unified view. MIS quarterly, 2003: p. 425-478.

(14) Bhattacherjee, A. and C. Sanford, Influence processes for information technology acceptance: An elaboration likelihood model. MIS quarterly, 2006: p. 805-825.

(15) Ajzen, I. and M. Fishbein, Understanding attitudes and predicting social behaviour. 1980.

(16) Rogers, E.M., Difiusion of innovations. New York: Free Press, 1983. 18(20): p. 271.

(17)Davis, F.D., Perceived usefulness, perceived ease of use, and user acceptance of information technology. MIS quarterly, 1989: p. 319-340.

(18) Gefen, D. and D.W. Straub, The relative importance of perceived ease of use in IS adoption: a study of e-commerce adoption. Journal of the Association for Information Systems, 2000. 1(1): p. 8.

(19)Zeithaml, V.A., A. Parasuraman, and A. Malhotra, Service quality delivery through web sites: a critical review of extant knowledge. Journal of the academy of marketing science, 2002. 30(4): p. 362-375.

(20) Dodds, W.B., In search of value: how price and store name information influence buyers' product perceptions. Journal of Services Marketing, 1991. 5(3): p. 27-36.

(21) Parasuraman, A., Reflections on gaining competitive advantage through customer value. Journal of the Academy of marketing Science, 1997. 25(2): p. 154-161.

(22)Zeithaml, V.A., Consumer perceptions of price, quality, and value: a means-end model and synthesis of evidence. The Journal of marketing, 1988: p. 2-22.

(23) Cronin, J.J., M.K. Brady, and G.T.M. Hult, Assessing the effects of quality, value, and customer satisfaction on consumer behavioral intentions in service environments. Journal of retailing, 2000. 76(2): p. 193-218.

(24) Chen, C.-F. and D. Tsai, How destination image and evaluative factors affect behavioral intentions? Tourism management, 2007. 28(4): p. 1115-1122.

(25) Fishbein, M. and I. Ajzen, Belief, attitude, intention and behavior: An introduction to theory and research. 1975.

(26) Bock, G.-W., et al., Behavioral intention formation in knowledge sharing: Examining the roles of extrinsic motivators, social-psychological forces, and organizational climate. MIS quarterly, 2005: p. 87-111.

(27)Kolekofski, K.E. and A.R. Heminger, Beliefs and attitudes affecting intentions to share information in an organizational setting. Information \& management, 2003. 40(6): p. 521-532.

(28) Taylor, S. and P.A. Todd, Understanding information technology usage: A test of competing models. Information systems research, 1995. 6(2): p. 144-176.

(29) Mathieson, K., Predicting user intentions: comparing the technology acceptance model with the theory of planned behavior. Information systems research, 1991. 2(3): p. 173-191. 